\title{
O PROJETO ENUNCIATIVO DA PÁGINA INSTITUCIONAL DE UMA IGREJA INCLUSIVA
}

\author{
THE ENUNCIATIVE PROJECT OF THE INSTITUTIONAL PAGE OF AN \\ INCLUSIVE CHURCH
}

\author{
Karina Giacomelli ${ }^{1}$ \\ Eduardo Soares da Cunha ${ }^{2}$
}

\begin{abstract}
RESUMO: Neste trabalho, analisamos, do ponto de vista enunciativo, a página institucional da Igreja Cristã Contemporânea (ICC), que se insere no campo religioso conhecido como "igrejas inclusivas". Essas entidades, de um modo geral, se propõem a não condenar as sexualidades não hegemônicas e a acolhê-las, e vêm chamando a atenção de pesquisadores brasileiros devido à significativa expansão no número de fiéis e congregações. Nos interessou, portanto, pensar de que forma uma dessas instituições atua no ciberespaço, realizando seu trabalho de divulgação e captação de novos adeptos por meio de um gênero discursivo que organiza esse projeto de dizer. Para isso, buscamos apoio nos pressupostos teóricos desenvolvidos pelo Círculo de Bakhtin e alguns de seus estudiosos. Nossa análise foi realizada a partir de uma proposta de Sobral (2009), em diálogo com Brait (cf., p. ex., BRAIT, 2006) sendo constituída das operações integradas de descrição, análise e interpretação do objeto de estudo. Os resultados obtidos mostraram que, ao mesmo tempo em que a instituição, que recorre a um entrelaçamento entre o discurso religioso e o discurso empresarial, apresenta-se como um novo espaço religioso para aqueles que se sentem excluídos de igrejas tradicionais também promove uma restrição de seu público-alvo.
\end{abstract}

PALAVRAS-CHAVE: Análise Dialógica do Discurso. Projeto Enunciativo. Igrejas Inclusivas.

ABSTRACT: In this paper we present the analysis from an enunciative point of view the institutional page of the Contemporary Christian Church (ICC), which is part of the religious field known as "inclusive churches". These entities in general propose not to condemn non-hegemonic sexualities and to welcome them and have been attracting the attention of Brazilian researchers due to the significant increase of the number of believers and congregations. It interested us, therefore, to think about the ways these institutions act in cyberspace, performing their work of dissemination and attracting new supporters by means of a discursive genre that organizes this enunciative project. For doing this, we have recourse to the theoretical assumptions developed by the Bakhtin Circle and some of its scholars. Our analysis was based on a proposal by Sobral (2009), in dialogue with Brait (cf., e.g., BRAIT, 2006) and consists of integrated operations of description, analysis and interpretation of the object of study. The results showed that the institution, which uses an interlacing strategy integrating religious discourse and business discourse, although presenting itself as a new religious space for those who feel excluded from traditional churches, also promotes a restriction of its intended audience.

KEYWORDS: Dialogical Discourse Analysis. Enunciative Project. Inclusive Churches

\section{Introdução}

As sexualidades que fogem ao padrão hegemônico e as representações de gênero em desacordo com o sexo biológico têm gerado uma grande discussão em nível nacional. Embora esse confronto se mostre mais visível na contemporaneidade, podemos identificar, no país, condutas intolerantes desde a chegada dos portugueses ao Brasil. Trevisan (2018, p. 63) destaca que, entre os costumes praticados pelos primeiros habitantes, nada chocava mais os cristãos da época do que o exercício do "pecado nefando", da "sodomia" ou da "sujidade", expressões atribuídas à homossexualidade em relatos da época.

\footnotetext{
${ }^{1}$ Doutora em Letras pela Universidade Federal de Santa Maria (UFSM). Docente da Universidade Federal de Pelotas (UFPEL). E-mail: karina.giacomelli@gmail.com

${ }^{2}$ Mestre em Letras pela Universidade Federal de Pelotas (UFPEL). E-mail: eduardosoaresrg@hotmail.com
} 
Volume 16 - Número 1 - jan/jul de 2021

Mas, assim como cantou Cassia Eller, em uma composição de Renato Russo "mudaram as estações e nada mudou" -, Lésbicas, gays, bissexuais, travestis (que somados a indivíduos que se identificam como transexuais, queer, intersexo, assexual e outros grupos com variações de sexualidade e gênero, que compõem o que é sinalizado com LGBTQIA+) continuam sendo vistos atualmente como pecaminosos por grande parte de um setor religiosoconservador, dentre outros.

A intolerância, que, para Droit (2017, p. 66), "vem do fato de que cada um está convencido de que seu universo é o único válido, o melhor, que constitui o único mundo verdadeiro" ganha voz e força política através do posicionamento de diversos parlamentares ligados a um núcleo que se diz em defesa da moral, da família e da nação. Com a força desse grupo, intensificada ainda mais com a condução de Jair Bolsonaro ao cargo de Presidente da República, a minoria político-identitária representada pela sigla LGBTQIA+ se vê em um verdadeiro conflito no que tange ao gozo de seus direitos de cidadãos.

No campo religioso, para além de todos os discursos de não aceitação pregados, os LGBTQIA+ enfrentam grandes dificuldades de inserção no tocante ao exercício da fé. Muitos são expulsos de congregações religiosas, ou até mesmo de seu convívio familiar, pelo simples motivo de exercerem uma sexualidade diferente daquela defendida e vista como "ideal" pelas concepções religiosas.

Diante disso e, considerando todo o contexto histórico-político-social (sobre)vivência dessas minorias, buscamos observar como alguns setores sociais têm reagido e resistido a esse cenário. Uma das reações é o surgimento de entidades religiosas ditas de teologia inclusiva. Essas denominações, que surgem no Brasil em meados dos anos 2000, alegam que buscam incluir todos aqueles que outrora foram excluídos das igrejas cristãs tradicionais. A partir disso, propomos a realização da análise do projeto enunciativo da página institucional da Igreja Cristã Contemporânea (ICC), procurando verificar como ela realiza este que é o objetivo das igrejas inclusivas.

Lorenzo (2016, p. 62) destaca que "as instituições religiosas de posicionamento inclusivo se destacam num momento propício ao conteúdo compartilhável em rede social virtual". Para o autor, essas comunidades religiosas, atentas ao cotidiano na Internet, consideram rentável investir esforços em campanhas institucionais nas redes sociais, visto que a evangelização nesses meios tem apresentado um melhor resultado na relação custo $\mathrm{x}$ benefício. Nosso interesse foi, então, pensar como essas instituições realizam, no ciberespaço, seu trabalho de divulgação e captação de novos adeptos, tomando esse objetivo como seu projeto de dizer, ou seja, o ponto de partida para a organização da página. Para alcançar os resultados, apoiamo-nos nos pressupostos teóricos e metodológicos desenvolvidos pelo Círculo de Bakhtin e em alguns de seus estudiosos.

\section{Contextualizando as igrejas inclusivas}

Como dissemos, a inserção religiosa de LGBTQIA+ não tem sido uma tarefa fácil, principalmente quando pensamos em esferas ligadas ao cristianismo. Entre os muitos casos de não aceitação que poderíamos trazer aqui, destacamos o de Troy Perry. Criado por pais evangélicos, o jovem, aos 15 anos de idade, tornou-se ministro batista de uma congregação na Flórida. Vivendo um conflito entre o discurso religioso e a sua sexualidade, resolveu, aos 18 anos, confessar ao seu pastor a atração que sentia por pessoas do mesmo sexo, tendo o eclesiástico the aconselhado a buscar um casamento heterossexual. Mais tarde, no Sul da Califórnia, procurou novamente o apoio da sua instituição, dessa vez sendo expulso. Diante da situação instaurada, refletindo sobre novas formas de continuar a exercer o cristianismo, 
fundou, em 1968, a primeira igreja inclusiva, denominada Metropolitan Community Church (MCC - Igreja Comunitária Metropolitana).

No Brasil, o surgimento dessas instituições acontece em outro momento. Em meados dos anos 1980, mais especificamente em 1984, durante a realização do $3^{\circ}$ Encontro Brasileiro de Homossexuais (EBHO), ocorreu uma discussão envolvendo o par homossexualidades versus religiosidades. Tal iniciativa abriu espaço para que grupos com interesse em debater essas questões se organizassem.

Facchini (2003) indica que, dando continuidade a essa abertura, surgiram, a partir de 1990, grupos religiosos que se mostravam mais flexíveis diante das questões ligadas às sexualidades marginalizadas. Como histórico do nascer desse novo cenário, destacamos o Grupo CORSA, que, entre 1996 e 1997, realizou cerimônias ecumênicas com uma grande presença de homossexuais. No mesmo sentido, surgiu no CAHEUSP (Centro Acadêmico dos Estudantes de História da USP), a iniciativa de oferecer um ambiente que também proporcionava a inserção de sujeitos não aceitos em outros espaços religiosos. Mais tarde, um grupo liderado pelo Pastor Cristiano Valério deu início ao processo de instauração da Comunidade Cristã Gay (CCG). Funcionando até 1998, a comunidade realizava a tradução de textos bíblicos disponibilizados no portal da Metrolpolitan Community Chruch (MCC).

Natividade (2008) chama a atenção para o fato de que, com a realização do trabalho realizado pelos grupos pioneiros e a instauração de um novo cenário houve uma "proliferação" de igrejas inclusivas em nosso país a partir do início dos anos 2000. Inicialmente concentradas no eixo Rio de Janeiro-São Paulo, hoje essas instituições se fazem presentes em muitos estados e cidades brasileiras. Em nosso caso específico, daremos especial atenção à Igreja Cristã Contemporânea (ICC), liderada pelo pastor Marcos Gladstone, cuja página institucional constitui nosso objeto.

Com base em informações disponibilizadas no site institucional da entidade, o nascimento da ICC se deu no dia 10 de setembro de 2006, em um encontro que contou com a presença de aproximadamente vinte pessoas no terceiro andar de um sobrado localizado no bairro da Lapa, do Rio de Janeiro. Somente mais tarde, com um público maior, atraído por meio da divulgação em outdoors e em diversas outras campanhas publicitárias, veio a instituição a ter um novo endereço, passando a ministrar seus cultos em um prédio situado no Centro da cidade. Com o público crescendo a cada celebração, houve nova mudança de endereço, para o bairro de Madureira, onde foi consagrada a sede nacional da Igreja Cristã Contemporânea, em 2011. No ano de 2015, a falta de espaço voltou a ser um problema, sendo fundada, também no bairro de Madureira, a Catedral Contemporânea.

Em seu Website, a instituição apresenta o seguinte objetivo:

[...] levar o amor de Deus a todos, sem preconceitos [...] através de um ministério que reflete a imagem do Senhor Jesus que adequou à sociedade e à cultura de seu tempo um chamado vivo de comunhão com Deus, acolhendo todos os excluídos, sem impedimento religioso algum. (IGREJA CRISTÃ CONTEMPORÂNEA, 2018)

Com um amplo trabalho realizado junto à mídia em geral, especialmente no ciberespaço, a denominação vem ganhando notoriedade. Atualmente, a ICC está presente em quatro estados brasileiros: Rio de Janeiro, São Paulo, Espírito Santo e Minas Gerais, totalizando onze templos. Sua presença nesses espaços vem possibilitando vivências religiosas para indivíduos vistos como "pecaminosos" em outras esferas religiosas. 
Volume 16 - Número 1 - jan/jul de 2021

\section{Algumas observações teóricas para fundamentar a análise}

Como já foi mencionado, buscamos no Círculo de Bakhtin e em alguns de seus estudiosos a fundamentação teórica para analisar nosso objeto, partindo da sua caracterização social da linguagem, que se constitui por meio da interação entre sujeitos, manifesta por enunciados.

De acordo com Volóchinov (2017), a língua deve ser pensada como um fenômeno social da interação verbal. Ao concebê-la dessa forma, não se está negando sua estrutura, mas afirmando que toda a atenção deve estar voltada ao processo interacional. Isso impõe pensar o modo como os sujeitos organizam seus enunciados, tendo em vista a situação comunicativa determinada em que se encontram, como o é, por exemplo, uma página institucional. A centralidade do ato verbal para essa concepção é destacada por Sobral:

a concepção de linguagem e de discurso proposta pelo Círculo de Bakhtin é essencialmente ativa, e, portanto, centrada no agente: o ato verbal, o processo de intercâmbio linguístico, no qual são produzidos os enunciados, e não apenas os enunciados/ discursos entendidos redutivamente como produtos de um significado fixado de uma vez por todas, constitui o objeto de estudo e o centro de seu empreendimento. (SOBRAL, 2009, p. 32)

Ao estabelecer um vínculo entre língua e contexto em termos da teoria aqui apresentada, aceita-se que não há um sujeito autônomo ou a língua como fenômeno dado a priori. Pelo contrário, é na/pela interação verbal que língua e sujeitos se constituem, e estes, mesmo mantendo sua singularidade, não são autárquicos. Como destaca Di Fanti (2003), tanto a linguagem como o sujeito constituem-se de modo dinâmico, em um ambiente histórico-social. Portanto, considerar a historicidade do sujeito em sua relação com o(s) outro(s) e com o mundo é uma das principais implicações do pensamento bakhtiniano.

Com efeito, o outro ocupa um papel tão importante quanto o eu que enuncia, de modo que, ao se dirigir ao(s) seus interlocutor(es), o locutor irá sempre levar em consideração não só seu objetivo de enunciar, mas em especial quem é/são seu(s) destinatário(s), que papéis sociais ocupa(m) e o que espera daquele(s) para quem emite seu dizer. Será em virtude destes e de outros fatores que os enunciados irão se inserir em determinados "gêneros do discurso" que, nas palavras de Bakhtin (2011, p. 262), podem ser entendidos como "enunciados relativamente estáveis". Tratando da vontade discursiva, diz Bakhtin que esta

se realiza antes de tudo na escolha de um certo gênero do discurso. Essa escolha é determinada pela especificidade de um dado campo da comunicação discursiva, por considerações semântico-objetais (temáticas), pela situação concreta da comunicação discursiva, pela composição pessoal dos seus participantes etc. A intenção discursiva do falante, com toda a sua individualidade e subjetividade, é em seguida aplicada e adaptada ao gênero escolhido, constitui-se e desenvolve-se em uma determinada forma de gênero. (BAKHTIN, 2011, p.282)

Diante disso, a cada tipo de cena enunciativa corresponderão certos gêneros discursivos, que poderão ser adaptados de acordo com o projeto enunciativo de cada interlocutor. O projeto enunciativo, ou projeto de dizer, deve ser visto, portanto, como aquilo que pretendemos enunciar em uma certa esfera de atividade com vistas a atingir determinados objetivos. Um exemplo disso pode ser dado a partir do caso que aqui analisaremos. Por meio de sua vontade enunciava, a instituição religiosa elabora um projeto de dizer com a finalidade de divulgar sua existência e atrair novos fiéis. 
Volume 16 - Número 1 - jan/jul de 2021

Ao realizar isso, estabelece relações dialógicas com todos os enunciados que antecedem seus atos enunciativos e com aqueles que os irão suceder, resgatando toda uma historicidade anterior a um aqui e agora e projetando-se no futuro. Assim, ao abordar uma questão como a aceitação religiosa de sujeitos LGBTQIA+, aquele que enuncia entra em diálogo (concordando ou não) com tudo aquilo que já foi e pode ser dito sobre tal temática.

Por meio desse diálogo, em contato com os enunciados outros e com as diferentes formas de ver o mundo, o locutor se posiciona a partir de sua condição específica de sujeito social, demarcando certas posições, visões sobre o que enuncia, atribuindo-lhe valores. A partir disso, destacamos que, para o Círculo, o signo é ideológico, pois, como destaca Faraco (2006), o pensamento de Bakhtin é radicalmente histórico, e o agir humano está vinculado a um universo valorativo, em que os sentidos dos enunciados serão sempre saturados de valores por índices sociais.

\section{A página da ICC e seu projeto enunciativo, ou projeto de dizer}

Para a realização da análise, recorremos à página institucional da ICC para a construção de nosso corpus e recorte para a análise. É importante mencionarmos que o Círculo de Bakhtin não traz uma metodologia de análise pronta e acabada, cabendo a cada analista elaborar seus próprios critérios analíticos de acordo com o objeto nos termos da concepção geral de linguagem. Para este momento, acreditamos ser pertinente o direcionamento dado por Sobral (2009). O autor, em diálogo com Beth Brait, sugere um caminho metodológico que passa pelos estágios de descrição, análise e interpretação do objeto em estudo.

$\mathrm{Na}$ descrição, olhamos para a materialidade enunciativa, observando de que maneira, neste caso, a página é apresentada ao seu destinatário. Com efeito, procuramos mostrar como o endereço eletrônico se mostra ao visitante. Posteriormente, ao pensar na análise, como apontam Sobral e Giacomelli (2016), devem ser ressaltadas as relações entre o plano linguístico e o enunciativo. Assim, pensamos em como as unidades da língua são mobilizadas e produzem sentidos nas esferas de atividade em que são enunciadas. Para finalizar, ao retomar as observações das etapas anteriores, interpretamos nosso corpus, refletindo sobre os sentidos advindos da inserção do texto examinado em uma dada situação de uso.

Para iniciar nossa exposição, apresentamos a página inicial da ICC. Esse olhar pode ser justificado quando pensamos ser essa a primeira visualização do visitante ao acessar o endereço da $W e b$. Assim, é por esse meio que vai se estabelecer a interação entre a instituição e seu interlocutor, aquele que procura a igreja. 


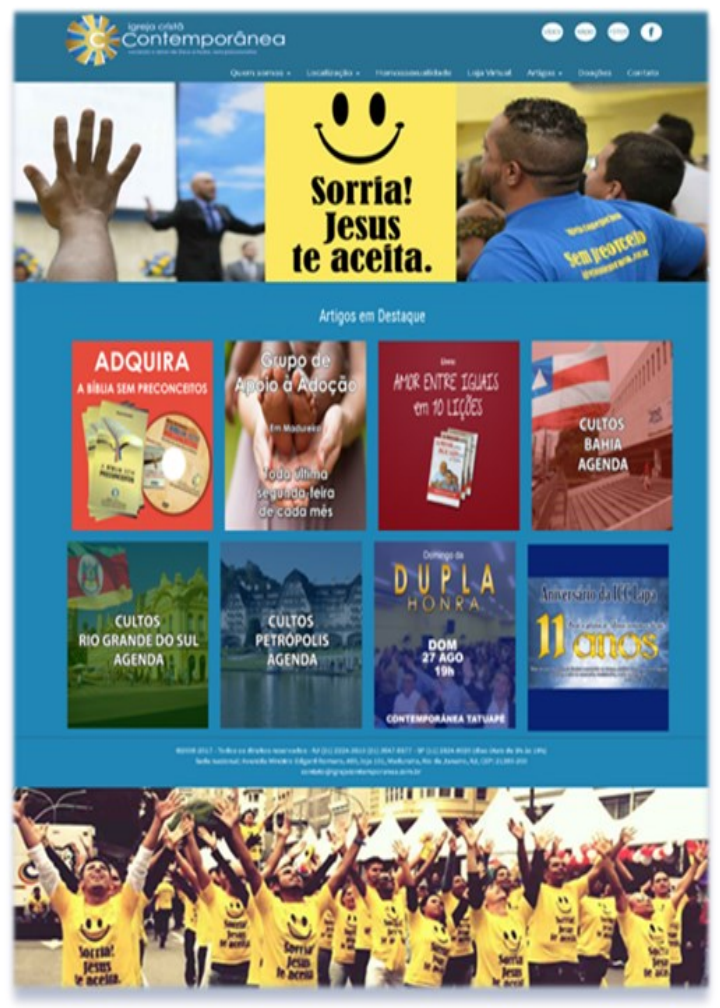

Figura 1: Página inicial da ICC.

Fonte: Igreja Cristã Contemporânea. Disponível em: http://igrejacontemporanea.com.br/. Acesso em: 01. Set. 2018.

A página analisada, assim como outras que se inserem no mesmo gênero, uma página institucional, traz em sua abertura a logomarca da instituição que representa, seguida do slogan da entidade: "Levando o amor de Deus a todos, sem preconceitos". Na sequência, temos a disponibilização de links: "Quem somos", "Localização"; "Homossexualidade"; "Loja Virtual"; Artigos"; Doações"; " e "Contato", bem como os ícones dos sites nas redes sociais. Ainda na parte de cima, há a foto de um culto, em que se sobressaem a figura do pastor de um lado e a de um casal homoafetivo masculino no outro lado de uma imagem com o seguinte enunciado "Sorria! Jesus te aceita". Esse mesmo enunciado estampa as camisetas do grupo retratado na parte inferior do website, na qual podemos observar uma outra foto que exibe algumas pessoas sorridentes e com os braços levantados, como em louvor. No centro, há quadros com informações sobre locais de cultos, obras à venda e indicação de um grupo de apoio à adoção. Convém indicar que o conteúdo desses quadros não é fixo, sendo este o que encontramos no momento da coleta do corpus.

Observando os enunciados que compõem a página, encontramos palavras provenientes de dois universos discursivos que se misturam, ou seja, há termos do campo empresarial e do campo religioso. No primeiro, os links de identificação, localização, contato e mesmo a logomarca configuram como exemplos de um campo alheio ao discurso religioso, mas que se justifica na medida em que, se uma igreja tradicional não precisa se identificar porque já é (re)conhecida, uma nova forma de organização também religiosa necessita "se apresentar, se mostrar, se vender". Desse modo, a igreja se confunde com uma empresa, o que é confirmado por links como "Doações" e "Loja Virtual".

A necessidade de identificação explica ainda um outro link, cujo título complementa a apresentação. Ao usar o enunciado "Homossexualidade", a página está definindo seu interlocutor ao mesmo tempo em que revela seu lugar dentre as igrejas. Ao singularizar o seu público-alvo, também mostra a valoração desse signo nesse contexto religioso específico. É o seu uso que confere à página o sentido de igreja inclusiva, revelando a sua visão, estampada no 
slogan em que se alude à aceitação de Jesus e corroborada pela imagem do casal homoafetivo na imagem e pela indicação de um livro intitulado "Amor entre iguais".

A partir de nossas observações, constatamos que as enunciações estão endereçadas a dois possíveis públicos, a saber: aqueles já inseridos na denominação religiosa e aqueles a quem visa atrair. Vemos, assim, que a página procura atender às expectativas de seus possíveis interlocutores, apresentando o que eles esperam encontrar e "antecipando", responsivamente, aquilo que o público que acessa o endereço gostaria de saber, seja para obter informações, seja para procurar conhecer a entidade e nela encontrar lugar para a manifestação de sua fé. Desse modo, é preciso que a endereçabilidade dos enunciados considere que eles devem referenciar coisas distintas, ainda que tendo como referencial geral a ICC. Por isso, cada um desses destaques demonstra como a página institucional mobiliza seus enunciados na situação de interação específica que quer estabelecer - entre ela e seus (possíveis) fiéis, um grupo específico representado pela sugestão de compra: "Bíblia sem preconceitos".

No slogan "levando o amor de Deus a todos, sem preconceitos", percebemos muito mais do que a revelação de uma marca, ainda que essa intenção comprove o imbricamento entre enunciados de diferentes esferas discursivas. Mas, o que temos também é a definição de uma igreja por meio de uma relação dialógica de oposição a outras, centrada na manutenção do propósito de toda congregação religiosa "levar o amor de Deus", com o acréscimo de "todos" e "sem preconceitos", o que a diferencia. Em linhas gerais o que se pretende é estabelecer um diferencial entre o "aqui" e o "lá", mostrando que "aqui" (na ICC) o interlocutor é aceito, independentemente de sua identidade sexual e/ou de gênero.

Vemos, portanto, que, para se singularizar como uma instituição religiosa e para agregar novos adeptos, a página dialoga com outros discursos religiosos, já ditos antes e que circulam nessa esfera de atividade, marcando sua posição em relações dialógica de oposição e diferenciação em relação a discursos anteriores. Ao mesmo tempo, projetivamente, são antecipadas relações de aceitação e acolhimento da profissão de fé daqueles a quem congregações clássicas ou tradicionais e pentecostais ou neopentecostais têm excluído pela orientação sexual. Ou seja, a página, ao organizar seus tópicos, busca estabelecer com seus interlocutores um diálogo que define seu tema (que, nesse sentido bakhtiniano, não se confunde com o tópico que aborda): mostrar àqueles que buscam ali conhecer a proposta da igreja que podem se sentir acolhidos, porque se trata de uma instituição inclusiva, e, consequentemente, pode se juntar a ela.

Assim, é possível verificar que o projeto de dizer, que organiza os links disponíveis em um todo de sentido, está voltado para a busca de um novo fiel que vai até o site na busca por informações. Esse objetivo de visita, que tomamos aqui como o norteador da página, é o que a leva, na elaboração de seu projeto enunciativo, a inserir itens como os já citados. Eles são uma parte essencial de um projeto que se mostra diferenciado, ainda que com os mesmos objetivos de qualquer igreja - conquistar fiéis.

Ainda na página inicial, devemos destacar a imagem que traz a mensagem "Sorria! Jesus te aceita". Se considerarmos que todo enunciado - e, por extensão, - todo o discurso tem um tema em torno do qual organiza seu dizer, e tomando como tema da congregação a aceitação em um espaço religioso de todos os excluídos pelas igrejas tradicionais, podemos perceber aqui um tópico discursivo cujo enunciado, "Jesus te aceita", significa, também, por extensão "A Igreja Cristã Contemporânea te aceita". É importante destacar que esse enunciado se relaciona a "Sorria, Jesus te ama", frequentemente utilizado por outras nomeações religiosas. A relação dialógica estabelecida, na retomada do discurso outro, é de identificação do discurso religioso, com destaque para a aceitação, uma vez que a expressividade do enunciado muda na troca de "ama" por "aceita". Ou seja, se mantém o princípio da fé, basilar em uma igreja, na figura da entidade que é o agente e do fiel que é quem recebe a ação. No caso, se Jesus o aceita, é porque 
o ama. E aquele que estava excluído (e, portanto, não amado) pode encontrar seu lugar num templo, numa congregação, que é para onde a página objetiva levá-lo.

Apresentamos até aqui as observações feitas por meio do primeiro contato do visitante com o endereço analisado. Agora, iremos iniciar a exposição dos enunciados presentes em alguns dos links da página. Em "Missão, Visão e Valores", disponível na aba "Quem somos", sublinhamos a importância que esses links exercem na busca por novos fiéis. Tais elementos costumam ser apresentados por empresas com o objetivo de demarcar uma determinada posição diante de um segmento, favorecendo a criação de uma identidade institucional. Desse modo, é assumido que estamos diante de uma congregação religiosa que pode ser comparada a uma empresa bem-organizada. Novamente, vemos o entrelaçamento entre discurso de esferas de atividade diferentes.

Quando olhamos especialmente para o espaço dedicado à "Missão", constatamos a presença daquele mesmo enunciado divulgado no slogan: "Levar o amor de Deus a todos, sem preconceitos". Entendendo que uma missão nada mais é do que um propósito a ser alcançado, ao pensar no verbo que é apresentado (levar), podemos dizer que essa palavra é usada pela entidade com o objetivo de se apresentar como uma espécie de mediadora entre o amor de Deus e os excluídos. É como se os interlocutores fossem vistos como um grupo que necessita de uma entidade que o conduza, nesse caso, a ICC.

Ponderando que essa "agência" é uma igreja inserida em um segmento de teologia inclusiva, ela necessita antecipar respostas a muitos de seus interlocutores que, diante daquilo que entendem como sendo uma instituição religiosa cristã, podem apresentar dificuldades em reconhecer a ICC como parte dessa mesma esfera. Talvez uma das respostas mais objetivas seja dada na apresentação da "visão" da entidade, em que temos: "Ser um ministério que reflete a imagem do Senhor Jesus, que adequou à sociedade e à cultura do seu tempo um chamado vivo de comunhão com Deus, acolhendo a todos os excluídos, sem impedimento religioso algum". (IGREJA CRISTÃ CONTEMPORÂNEA, 2018). São itens lexicais como "comunhão", "chamado" e "Senhor Jesus" que expressam uma vinculação ao discurso religioso cristão, fazendo assim com que os destinatários do endereço eletrônico reconheçam a entidade como tal. Por outro lado, ao mostrar isso, a página expõe também uma nova posição frente aos ideais religiosos, por meio de um ministério que se "adequou" ao seu tempo.

Essa vinculação é ainda corroborada em "Fundador". Assim que abrimos a aba, visualizamos uma imagem do pastor Marcos Gladstone vestindo um terno de cor chumbo e com os olhos fechados, em um momento de concentração. Na esfera religiosa, de um modo geral, a conexão com Deus é o que muitos desejam. Não podemos deixar de mencionar, também, o diálogo que é instaurado entre essa imagem e os cultos neopentecostais, em que o "estar diante de Deus" é algo extremamente valorizado. A cor da vestimenta, por sua vez, instaura um diálogo entre o novo e o tradicional, quando consideramos que pastores geralmente utilizam trajes na cor preta, mas que, atualmente, a moda "determina" a cor azul como a mais moderna. Assim, ao optar por uma tonalidade que fique em um meio termo (preto/ azul), é possível flutuar entre o tradicional e o novo. E é exatamente por meio dessa flutuação que a ICC pretende e precisa ser vista. Do mesmo modo que é necessário apresentar sua diferenciação frente às demais, também é extremamente valioso ter algo que se apresente de forma semelhante e contribua para a criação da imagem de uma igreja cristã em seu sentido mais amplo.

Dando continuidade ao link "Quem somos", no sublink denominado "História", temos:

A Igreja Cristã Contemporânea não é mais uma igreja, mas a representação do amor incondicional de Deus por um povo que sofria a dor da exclusão. Desta forma, na contramão de um cenário opressor e um sistema religioso muitas vezes intolerante e alheio às necessidades das minorias (sempre acolhidas pelo Senhor Jesus), o Espírito Santo ergueu a Igreja Cristã Contemporânea como 
Volume 16 - Número 1 - jan/jul de 2021

uma resposta a tantos séculos de preconceito. (IGREJA CRISTÃ CONTEMPORÂNEA, 2018)

Ao dizer que a ICC "não é mais uma igreja", o enunciado procura novamente estabelecer um diferencial entre a instituição representada e as demais. Aqui, ligamos a qualificação "incondicional" à escolha por "sofria", um pretérito imperfeito, que se refere a um fato ocorrido no passado, mas que não foi completamente terminado, expressando, assim, uma ideia de continuidade e de duração no tempo. Ou seja, os homossexuais ainda sofrem a dor da exclusão por não participarem de uma igreja, o que pode mudar caso entrem para a ICC. O cenário religioso dominante não é esquecido, ao contrário, é trazido para lembrar que a ICC não comunga com postura semelhante. Nesse sentido, é significativa a escolha pela palavra "contramão".

Vemos, mais uma vez, como é difícil para uma igreja inclusiva se colocar ao lado das tradicionais, que estariam no "lado certo". Ainda assim, como é lembrado, elas oprimem e se mostram alheias às necessidades das minorias, ao contrário de Jesus, que sempre as acolhe e do Espírito Santo, por quem a congregação foi erguida. Logo, se existe um Senhor Jesus, acolhedor das minorias, onde está uma instituição que também as acolha? A página analisada procura de todo o modo responder a esse questionamento, colocando-se contra a postura das que estariam na direção "correta".

Outro ponto que deve ser destacado é a descrição da trajetória percorrida pela entidade. Os números, tanto de fiéis quanto de novas filiais, são expostos sempre que possível. Ao mostrar que muitas pessoas frequentam a instituição, é conferida uma legitimação de um espaço considerável de ser também frequentado pelo visitante. Essa estratégia pode ser comparada a um recurso frequentemente utilizado pela publicidade ao nos dizer "Venha você também", isto é, “Muitos já estão conosco. O que você está esperando?". Estas foram as considerações obtidas por meio da abertura dos links disponibilizados na aba "Quem somos". Na sequência do nosso texto, damos continuidade às nossas observações.

Como comentamos, há uma aba referenciada como "Homossexualidade". Nesse espaço, nos é informado que mais informações sobre o assunto podem ser encontradas em vídeos produzidos pelo pastor Marcos Gladstone sobre a Teologia Inclusiva. Ao todo, são exibidos 24 vídeos. Entre os títulos, figuram: "Ser cristão e homoafetivo", "O dia que Jesus encontrou um gay", "Gays: céu ou inferno?", "Deus não faz acepção de pessoas" e "Gays na Bíblia".

Como podemos verificar, a questão da homossexualidade masculina aparece como central no material produzido por Gladstone. Não encontramos, por exemplo, vídeos que versem sobre a aceitação de lésbicas, travestis e transexuais. Somente um vídeo é intitulado de "Bissexualidade na Bíblia". Os títulos apresentados se mostram diretos e objetivos. Mais uma vez, foi possível percebermos o endereçamento a um público em específico, nesse caso, os homossexuais. Destacamos que os títulos conversam com muitos dos anseios da população LGBT. Como exemplo disso, podemos citar o título "Gays: céu ou inferno?", em que é estabelecido um diálogo com uma das preocupações causadas pelos famosos "textos de terror" que, ao condenarem a homossexualidade, dizem que as pessoas que cometem tal pecado irão para o inferno. A utilização de uma pergunta ao inserir esse título, mostra que, segundo a visão da ICC, essa é uma das dúvidas do seu público e, partir disso, ao considerar uma responsividade ativa, traz enunciados como o exemplificado.

Para finalizar, mencionamos a exibição da aba "pregações", em que são disponibilizados 52 vídeos. No entanto, diferentemente dos outros que eram elaborados e pensados enquanto recursos audiovisuais, estes, em sua maioria, são resultantes de gravações das pregações realizadas no interior da congregação, mostrando-se como um interessante material tanto para aquele público que já frequenta a denominação quanto para aqueles que buscam por informações. 
Volume 16 - Número 1 - jan/jul de 2021

Lembramos que todas as escolhas realizadas pela página, como ocorre com todo outro enunciador, foram feitas em detrimento de outras possíveis, o que indica o ponto de vista valorativo do locutor ICC. Em outros termos, questões como "Que informações são mais relevantes para o projeto de dizer? Como organizá-las? Em que ordem? Onde inseri-las?" remetem aos elementos que motivaram as escolhas feitas e é a partir de sua consideração que visualizamos o endereço eletrônico analisado do modo como o fizemos Desse modo, ao determinar como relevantes tópicos de campos discursivos distintos, a igreja se apresenta não só como uma instituição inclusiva, mas também "moderna", no sentido não apenas do públicoalvo, mas da sua organização, o que traz uma credibilidade que vem do campo de atuação empresarial. Isso se comprova com a inserção de links que remetem a esse universo.

\section{Considerações finais}

As igrejas inclusivas, tal como são denominadas por diversos estudiosos, nos chamaram a atenção pela possibilidade da prática da fé por indivíduos outrora não aceitos no ambiente religioso cristão. A partir do objetivo proposto, procuramos mostrar como uma dessas entidades tem trazido para dentro de suas congregações sujeitos que até então eram considerados em "desacordo" com o divino. E, mais especificamente, como usa a linguagem para isso, valorando enunciados do campo do discurso religioso e do discurso empresarial com objetivos específicos.

Ao considerarmos a página institucional no início do estudo, esperávamos um endereçamento geral, ou seja, todo o público LGBTQIA+. Porém, diferentemente do que pensávamos e até mesmo da forma que uma apreciação menos detalhada mostrava, inclusive considerando o slogan exibido ("Levando o amor de Deus a todos, sem preconceitos"), o Website se inclina para um público muito mais específico do que escolhas lexicais como "todos" e "LGBT" sugerem, qual seja o de homossexuais masculinos (gays, designados pela letra $\mathrm{G}$, na sigla).

O conteúdo da página centrado nesse grupo representa uma restrição em se tratando de uma igreja inclusiva. Se podemos pensar que o surgimento desse tipo de congregação religiosa deu-se em função da demanda justamente desse grupo, o que justificaria esse fechamento, a luta pela visibilidade de outros grupos representados na sigla (que inclusive levou à modificação da forma LGB inicial em LBGT e, atualmente, em LGBTQIA+) é hoje uma realidade em vários segmentos da sociedade.

Uma página institucional, na grande maioria dos casos, visa realizar uma apresentação e/ou venda de uma ideia ou produto. Na presente situação, verificamos que a entidade não somente se apresenta para o seu seleto público como também procura vender-se. Para isso, são utilizados diferentes recursos estilísticos. Notamos que, primeiramente, e isso se dá inclusive na disposição das informações ao considerar o segmento de leitura possível de ser percorrido pelo interlocutor, são apresentadas informações mais gerais, como: missão, visão, valores, história, fundador, localização etc.

Vemos, então, imbricados, o discurso religioso e o discurso empresarial. Dessa forma, ao se apresentar, a igreja faz isso recorrendo a um modelo que é o mesmo em uma empresa, em um negócio. A recursos que poderíamos entender apenas como uma "apresentação institucional", é adicionada uma série de outras informações que nos permitem valorar a entidade como uma empresa religiosa, o que nos leva a concluir que o seu projeto de dizer é organizado para convencer o interessado a engajar-se na congregação. Portanto, concomitantemente com a apresentação, temos a venda de uma ideia: a possível aceitação do visitante e a sua comunhão com Deus, livrando-o de todas as formas de preconceito, tendo como agente a instituição.

Os resultados obtidos nos mostraram que, mesmo diante de um novo olhar dessa instituição para com as sexualidades dissidentes, certas posturas adotadas nas esferas religiosas 
Volume 16 - Número 1 - jan/jul de 2021

mais tradicionais foram mantidas no ambiente virtual da entidade. Outra atitude observada foi o direcionamento dos textos do endereço eletrônico a um interlocutor específico, o que reduz o universo inclusivo específico da instituição.

É importante destacarmos que não tivemos por objetivo realizar uma análise da instituição, apontando-a como cabível ou não de ser frequentada. Isso cabe a cada interlocutor. $\mathrm{O}$ que procuramos foi, acima de tudo, mostrar como o projeto do Website se apresenta, considerando o diálogo com seus interlocutores e com discursos, passados e/ou futuros. Por fim, destacamos a importância de entidades como a ICC e esperamos que as contribuições aqui trazidas possam suscitar novos diálogos.

\section{Referências}

BAKHTIN, M. Estética da criação verbal Trad. Paulo Bezerra. 6. ed. São Paulo: Martins Fontes. 2011.

BRAIT, B. Análise e Teoria do Discurso. In: BRAIT, B. (Org.). Bakhtin: Outros ConceitosChave. São Paulo: Contexto, 2006. p. 9-31.

DI FANTI. M. A linguagem em Bakhtin: pontos e pespontos. Veredas: Revista de Estudos da Linguagem. Juiz de Fora. V.7, n.1 e n.2. p.95-111, 2003.

DROIT, R. Tolerância: O que é? Por que é importante? É possível nos dias de hoje? Como educar para a tolerância? Trad. Patricia Reuillard. São Paulo: Editora Contexto, 2017.

FACCHINI, R. Movimento homossexual no Brasil: recompondo um histórico. Cad.AEL. Campinas, v.10, n.18/19, p.82-123, 2003.

FARACO, C. O estatuto da análise e interpretação dos textos no quadro do Círculo de Bakhtin. $1^{\circ}$ Encontro Internacional do Interacionismo Sociodiscursivo. 1 ed. PUC-SP, junho de 2006. Disponível em: http://www.pucsp.br/isd/artigos/Conferencia_\%20faraco.pdf. Acesso em: 18 out. 2018.

IGREJA CRISTÃ CONTEMPORÂNEA. Disponível em: http://igrejacontemporanea.com.br. Acesso em: 01. set. 2018.

LORENZO, D. Tecnologia inclusiva nas redes sociais: evangelização inclusiva segundo a Igreja Comunidade Metropolitana em João Pessoa. 103f. 2016. Dissertação de Mestrado PPGC, Universidade Federal da Paraíba, João Pessoa, 2016.

NATIVIDADE, M. Deus me aceita como eu sou? A disputa sobre o significado da homossexualidade entre evangélicos no Brasil. 342 f. Tese de doutorado- PPGSA, Universidade Federal do Rio de Janeiro, Rio de Janeiro, 2008.

SOBRAL, A. Do dialogismo ao gênero: As bases do pensamento do Círculo de Bakhtin. Campinas: Mercado de Letras, 2009.

SOBRAL, A; GIACOMELLI, K. Gêneros, marcas linguísticas e enunciativas: uma análise discursiva. In: SOBRAL, A (org); SOUZA, S. (org). Gêneros, entre o texto e o discurso. São Paulo: Mercado de Letras, 2016. p. 47-69.

TREVISAN, J. Devassos no Paraíso: a homossexualidade no Brasil, da colônia à atualidade. 4. Ed. Rio de Janeiro: Objetiva, 2018.

VOLÓCHINOV, V. Marxismo e filosofia da linguagem. Trad. Sheila Grillo. São Paulo: Editora 34, 2017. 